\title{
A Review of Bilingual Teaching in Colleges and Universities
}

\author{
Jun Rao \\ Tianjin University of Finance and Economics, China \\ rjnew@sina.com
}

\begin{abstract}
This paper analyzes and summarizes Chinese research literatures on bilingual teaching since 2001 . There are the following three parts. Firstly, in the fields of traditional bilingual teaching models and methods, researchers paid more attention to three factors, teachers, students and teaching materials. Secondly, considering the influence of MOOC on bilingual teaching, researchers focused on improving the efficiency of bilingual teaching with MOOC mode. At last, in order to evaluate the efficiency of bilingual teaching, some researchers tried to construct an evaluation index system with AHP or other methods. Moreover, through this evaluation system, we can find out which factor is the most important factor for raising the level of bilingual teaching.
\end{abstract} \section{MOOC}

Keywords-Review; Bilingual Teaching; Evaluation System;

\section{INTRODUCTION}

In 2001 the Ministry of education point out several opinions on strengthening undergraduate education to improve the teaching quality of the proposed undergraduate education should create conditions for using English or other foreign language in all kinds of professional courses. The Ministry of education proposed in this file to actively promote using English or other foreign language teaching in accordance with the education should be oriented to modernization, the global and the future. In order to adapt to the economic globalization and technological revolution, undergraduate education should create conditions to use English or other foreign language in the professional courses.

Moreover, in the area of high-tech biotechnology, information technology professionals, in order to adapt to the financial, legal and other professional needs after China's accession to the WTO, we should prompt foreign language teaching to the curriculum of $5 \% \sim 10 \%$ in three years. It is specially stipulated that bilingual teaching should be adopted in $15 \%$ of the specialized courses in key universities. Other colleges and universities should also make the rate up to $3 \%$.

Since then, bilingual teaching theory and method of research rose up in China.

\section{TRADITIONAL BILINGUAL TEACHING RESEARCH}

On the one hand, the problem of university management system and policy were very important. Han Shuwei (2007) took the questionnaire survey of those bilingual teaching backbone teacher training in Higher Education of the Ministry of education, this paper points out that the establishment of bilingual teaching objectives, to provide policy and financial support, strengthen the construction of teaching staff, improve the incentive mechanism of university bilingual teaching problems [1].

Deng Juntao (2009) believes that the bilingual teaching process is mainly affected by three factors, namely teacher factors, student factors and teaching material factors. It is pointed out that the bilingual teaching should be carried out smoothly from the aspects of teacher training, student selection and teaching material selection [2].

Sun Chaoping et al. (2008) from the faculty construction, teaching mode, teaching materials, teaching atmosphere, teaching effect of incentive measures, security aspects of the positive measures taken by key universities in China in the process of bilingual teaching, and points out the further deepening of bilingual teaching reform should pay attention to the problem: to strengthen the construction of teaching team, based on the constructivism teaching mode to provide teaching resources, the use of modern educational technology to reduce the rich bilingual teaching difficulty, focus on cooperation and exchanges, promote the construction of bilingual courses, guidance [3].

On the other hand, the aspect of bilingual teaching practice can't be ignored. Li Wenlii (2006) proposes that the current bilingual teaching has the following problems: reducing the amount of professional knowledge, reducing the absorption rate, and consuming too much time for students to review and so on [4].

Kang Shumin (2008) proposed that we should start from the teaching media and language based on different curriculum objectives and characteristics, and pave the way for such modes, such as the multilevel bilingual teaching mode, English introduction, integration between English and Chinese and English immersion [5].

Wan Lihong (2006), Tian Hejun and Guo Zhenping (2010), Qi Wenyan and Liu Lanfang (2011) respectively made the practices of bilingual teaching, put forward the situational 
teaching method, information technology, and task-based teaching method. They proved that these models and methods are in varying degrees to effectively promote the bilingual teaching [6-8].

Yin Chunlin (2006) analyzed the effection of the selection of method and the continuity of bilingual teaching on the teaching [9]. Moreover, Lv Fenghua (2012) emphasized the importance of students' sense of self efficacy in bilingual teaching [10].

Liu Zhaolong et al. (2012) performed experiments through interactive feedback system of bilingual class and general course, and the results showed that $40 \%$ of the students can read the original English textbooks, and they are willing to accept bilingual teaching, and the effect is good. Research shows that when teachers adopt appropriate teaching mode and method, can greatly reduce the students' anxiety [11].

Lv Jingyu (2016) retrieved those papers published in CNKI Core Journals of bilingual teaching between 1994 and 2015. The study found that effective implementation of bilingual teaching in colleges and universities was beneficial to students' language ability and English subject frontier knowledge understanding. Meanwhile more than half of the students love the bilingual teaching, discussion English textbooks of English classroom use rate is about $30 \%$ to - $50 \%$ disagree [12].

\section{RESEARCH ON BILINGUAL TEACHING UNDER THE INFLUENCE OF MOOC}

After 2012, the MOOC, the abbreviation of Massive Open Online Courses, as a new teaching mode in the United States, provides a wide range of learning tools and rich curriculum resources, breaking the traditional course of the limit of time and space, has brought huge impact to the traditional university education around the world. With the introduction of MOOC and flipped classroom, the scholars began to face the influence of this revolutionary teaching mode on bilingual teaching.

Wang Zhuli et al. (2015) agreed that the mobile Internet marked by smart phones poses a serious challenge to traditional classroom teaching, and network education will subvert the traditional education and teaching model [13]. Bi ran (2015) thought that the combination of traditional classroom teaching and the Internet to expand the education of time and space, conducive to improving the quality of teaching, but also to the teachers in the classroom teaching activities, data processing, information collection and effective use of such challenges [14].

Ma Guangqiang (2016) and so on have investigated the students' Extracurricular active learning MOOC, found that contemporary college students have a good level of English, $80 \%$ of the students are willing to take the initiative to learn foreign MOOC courses [15].

With the teaching concept of MOOC gradually being familiar with and accepted by the majority of teachers and students, scholars began to study the practice of MOOC. Based on building model, Xia Shiwu (2016) believes that the advantages of the network classroom with organic combination of traditional physical classroom and Internet support can complement each other to play the new teaching mode, to resolve the current college students lack of learning motivation, indulge in network roaming, personnel training quality crisis[16].

Liao Shumei (2016) constructed a new bilingual teaching model with the view of resource development, autonomous learning before class, knowledge internalization in the course, learning activity evaluation, summary and reflection on the learning process, and proved that it promoted the students' independent and personalized learning [17].

Mu Lan and Qi Chunlin (2016) pointed out that the mode of the classroom via internet is a new teaching mode, and it is a combination of the following three elements, the Internet technology, teaching methods and teaching contents [18].

Gu Musong et al. (2015) attempted to reform the teaching mode of bilingual teaching for the course introduce the basic courses of computer, by recording the micro videos for MOOC, increasing after-class exercises and tests, using flipped classroom teaching method, attempted to solve the traditional problems in bilingual teaching [19].

Zhou Yuqing et al. (2016) studied on related topics about MOOC, micro class, flipped classroom, combined with classroom application and teaching practice, interfered with comparative analysis of network teaching and classroom teaching characteristics and functions [20].

Zheng Jiping and Zhang Siman (2016) put forward the solutions of grading teaching and introducing MOOC open teaching to solve some problems, such as the uneven distribution of students' English level and the disadvantages brought by traditional teaching methods [21].

\section{RESEARCH ON BILINGUAL TEACHING EVALUATION SYSTEM}

The establishment of bilingual teaching evaluation system needs to find out the main factors affecting bilingual teaching and scientifically determine the weight of each factor.

From the perspective of teaching theory, Zhang Siteng (2013) argued that the influence factors of bilingual teaching are student factor, teaching materials factor and teaching activities factor. The student factor includes English level, theory basic and learning attitude. The teaching materials factor includes English edition textbook, Chinese translation reference books and professional vocabulary. The teaching activities factor includes English teaching hours, curriculum design and teacher's level [22].

Wang Jun (2013) agreed that the perspective of students is an important manifestation of inquiry learning. It is not only an extension of classroom teaching, optimize the talent training mode, but also reflect in the interactive emotion teaching, and promote the healthy development of students' personality [23].

Cao Qiaoqiao (2013) thought that the students are the biggest beneficiaries of higher education, teachers must use the existing knowledge and experience, feedback activities to improve their educational activities. This paper supported to see the students as curriculum designer, and make a common 
teaching mode analysis framework, thus study the degree of student's participation in curriculum design [24].

Min Haiyan (2015) stressed that the end of the process control and evaluation of teaching conditions are equally important, and created a set of three level evaluation index system from the three aspects of teaching conditions, process monitoring and teaching effect. This paper mainly adopted expert evaluation, students' self-evaluation evaluation methods. The evaluation system is shown as table I [25].

From the perspective of empirical research, Liu Zhaolong (2012) made a survey on more than 2000 students majored in science and engineering, and analysed the questionaries based on the method of analysis of variance and feedback of the teaching system. Finally he draw the conclusion that bilingual teaching is not suitable for some specialized courses, because it will strongly increase students' learning difficulty [11].

Zhang Siteng (2013) applied AHP method to research three major factors, students, teaching materials and teaching activities, which affect the bilingual teaching. After using statistical method of chi square test respectively, some advices are presented to improve the effectiveness of the bilingual teaching [22].

Wang Qin et al. (2017) constructed the evaluation system by the following four aspects: the rationality of the bilingual course, the achievement of the teaching objectives, the implementation efficiency and the sustainability of the bilingual education. They found that the standard of attainment and the efficiency of execution are important indicators [26].

TABLE I. THE EVALUATION SYSTEM OF BILINGUAL TEACHING

\begin{tabular}{|c|c|c|}
\hline LEVEL 1 & LEVEL 2 & LEVEL 3 \\
\hline \multirow{9}{*}{ Teaching Condition } & \multirow{3}{*}{ Teacher } & Professional Ability \\
\hline & & Teaching Ability \\
\hline & & Foreign Language Ability \\
\hline & \multirow{3}{*}{ Student } & Bilingual Teaching Awareness \\
\hline & & Foreign Language Ability \\
\hline & & Professional Ability \\
\hline & \multirow{3}{*}{ Teaching Materials } & Matching Degree Of Teaching Materials \\
\hline & & \\
\hline & & Abundance Of Teaching Material Resources \\
\hline \multirow{6}{*}{ Teaching Process } & \multirow{3}{*}{ Content Of Teaching } & Clearance And Accuracy Of Teaching Content \\
\hline & & Focus And Difficulty Prominent \\
\hline & & Localization \\
\hline & \multirow{3}{*}{ Teaching Methods } & Bilingual Integration Degree \\
\hline & & \\
\hline & & Bilingual Comprehension \\
\hline \multirow{4}{*}{$\begin{array}{l}\text { Teaching } \\
\text { Effectiveness }\end{array}$} & \multirow{3}{*}{ Target Of Professionals } & Examination Evaluation \\
\hline & & Student Evaluation \\
\hline & & Expert Evaluation \\
\hline & Target Of Foreign Language & Self Assessment Of Students \\
\hline
\end{tabular}




\section{SUMMARY}

In summary, we can see that the literature on bilingual teaching reform in domestic colleges and universities basically reflects the trends of teaching ideas and methods. Especially the revolutionary network class teaching mode brings new challenges and opportunities for bilingual teaching. At present, domestic researchers mainly focus on the improvement of teaching mode and methods, yet pay less attention to the evaluation of teaching effectiveness, especially the evaluation system of bilingual teaching reform based on the MOOC idea, which will be more important field.

\section{REFERENCES}

[1] Han Shuwei, Zhu Chuanchen, Wang Xiaojun. The exploration and practice of bilingual teaching problems faced in bilingual teaching and Countermeasures -- University of International Business and Economics carried out in Colleges and universities [J]. Journal of Peking University (PHILOSOPHY AND SOCIAL SCIENCES EDITION), 2007, (S2): 8486.

[2] Deng Juntao Zhu Xiaoshen, twenty-first Century. Our bilingual teaching research [J]. China Education Innovation Herald, 2009, (25): 69.

[3] Sun Chaoping, Liu Yezheng, Ren Minglun. Key measures to promote bilingual teaching in Colleges and universities of China $[\mathrm{J}]$. review of teaching and research, 2008, (06): 514-517.

[4] Li Wenli. Effect analysis and improvement approach of bilingual teaching [J]. Liaoning education research, 2006, (06): 60-61.

[5] Kang Shumin. Construction of bilingual teaching mode from the perspective of teaching language use -- Taking bilingual teaching practice in local universities as an example, $[\mathrm{J}]$. foreign language circles, 2008, (06): 64-70.

[6] Wan Lihong, Lai Shuying, Lin Xiyin, Yan Weiqing, Zhao Feiying. Application of $[\mathrm{J}]$. and the effect of situational teaching in bilingual teaching in Chinese Journal of nursing, 2006, (03): 251-253.

[7] Tian Hejun, Guo Zhenping. Research on network aided stereoscopic bilingual teaching system $[\mathrm{J}]$. teaching and management, 2010, (36): 145-146.

[8] Qi Wenyan, Liu Lanfang. The task-based teaching in bilingual teaching of higher vocational nursing practice in $[\mathrm{J}]$. Vocational Education Forum, 2011, (05): 94-96

[9] Yin Chunlin, Wei Jiaping, Zhang Shuyun, Fan Jie, Li Darong. Effect evaluation and influencing factors analysis of bilingual teaching of clinical medicine in 7 year program [J]. Chinese Journal of hospital management, 2006, (05): 314-316

[10] Lv Fenghua. Research on students' self efficacy in bilingual teaching [J]. educational exploration, 2012, (03): 140-142.
[11] Liu Zhaolong, Luo Ying, Hu Haiyun. Empirical analysis of bilingual teaching in Colleges and universities [J]. Chinese university teaching, 2012, (05): 58-60.

[12] Lv Jingyu. Current situation of empirical study on Bilingual Teaching in China [J]. Journal of Hunan Tax College, 2016,29 (02): 63-65.

[13] Wang Zhuli, Li Xiaoyu, Lin Jin. The intelligent mobile phone and "Internet plus" classroom teaching integration of information technology and the new thinking and new path $[\mathrm{J}]$. Journal of distance education, 2015,33 (04): 14-21.

[14] $\mathrm{Bi}$ ran. "Internet plus class" under the background of University Teachers' occupation ability to challenge $[\mathrm{J}]$. and Countermeasures of modern educational management, 2015, (12): 50-55.

[15] Ma Guangqiang, Wang Qian, Wan Hongjiao, ye kahei. Bilingual teaching environment investigation and evaluation system for students under the environment of MOOC [J]. college, 2016, (04): 84-85.

[16] Xia Shiwu. "Double classroom teaching model of College Internet plus" the background of the construction and operation of $[\mathrm{J}]$. national education administrative college, 2016, (05): 42-47.

[17] Liao Shumei. "Internet plus education under the background of College English classroom teaching mode construction of Jiamusi $[\mathrm{J}]$. turnover. Journal of Career Academy, 2016, (07): 360-362.

[18] Mu Lan, Qi Gong. Teacher curriculum integration: realistic problems and ways of realization [J]. educational exploration, 2016, (02): 113-116

[19] Musong tour, Lei, Zhang Zhiqiang. MOOC computer basic course reform of bilingual teaching of $[\mathrm{J}]$. based on information system engineering, 2015, (08): 157-158.

[20] Zhou Yuqing, Shuyu million. "Internet plus" under the background of Classroom Teaching -- MOOCes, micro class, flip the classroom analysis and thinking of $[\mathrm{J}]$. Chinese education informatization, based on the 2016 (02): 10-12+39.

[21] Zheng Jiping, Zhang Siman. Database principle of bilingual teaching of computer education under the new situation of [J]., 2016, (07): 122-125.

[22] Zhang Sternberg, Wang Hui, Xu Funing, Sun Yunqing. [J]. physics and engineering empirical analysis of the influencing factors on the effect of bilingual teaching, 2013,23 (04): 54-57.

[23] Wang Jun. Inquiry learning: a new way to improve the effectiveness of bilingual teaching in Colleges and universities [J]. Jiangsu higher education, 2013, (02): 68-69.

[24] Cao Qiao, Zhang Baohui, Liu Yonggui, Liang Leming. Students as curriculum co designers: Research on the design of bilingual course for Postgraduates Based on introduction to learning science [J]. open education research, 2013,19 (06): 51-61.

[25] Min Haiuyan. On the construction of bilingual teaching quality evaluation system in Universities $[\mathrm{J}]$. education and profession, 2015, (10): 78-80

[26] Wang Qin, Weng. Study on the evaluation system of [J]. Chinese medical university management informationization bilingual courses in Applied Undergraduate Based on AHP, 2017,20 (11): 222-226. 